\title{
Incorporating PDA Use in Diabetes Self-Care: A Central Texas Primary Care Research Network (Cen'TexNet) Study
}

\author{
Samuel N. Forjuoh, MD, DrPH, Michael D. Reis, MD, Glen R. Couchman, MD, \\ Marcia G. Ory, PhD, MPH, Saundra Mason, BSN, RN, and Susan Molonket-Lanning
}

Introduction: We investigated the feasibility of incorporating the use of the personal digital assistant (PDA) in diabetes self-care in primary care.

Methods: Adults with type 2 diabetes whose last measured HbA1c value was $8.0 \%$ or greater were recruited from 4 family practice clinics. A trained research assistant provided one-on-one training on the use of a loaned PDA preinstalled with Diabetes Pilot software.

Results: Of 550 potential subjects invited for participation, only $98(17.8 \%)$ called to schedule an orientation visit. However, 18 were never contacted when the recruitment goal was reached. Of the remaining 80 respondents, $43(53.8 \%)$ met all study inclusion criteria. Participants' mean age was $\mathbf{5 5 . 2}$ years $(S D=10.1)$. The majority were female $(62.8 \%)$ and white $(62.8 \%), 83.7 \%$ had at least some college education, and most reported an income of $\$ 30,000$ to $\$ 69,999$. The mean baseline HbA1c was $10.0 \%(S D=1.5)$. Major challenges of concern to the practicing family physician included few subjects agreeing to participate even though it was free, subjects who agreed to participate being generally different from those who decided not to participate, some PDAs not returned, and the relatively high cost of the intervention.

Conclusions: Attempts to incorporate PDA use in diabetes self-care may be significantly challenging, although feasible. We identified several challenges and suggest strategies to overcome them. (J Am Board Fam Med 2007;20:375-384.)

Evaluating the impact of emerging health information technology or e-health on disease outcomes and its cost effectiveness has been a continuing challenge to health care providers. ${ }^{1,2}$ As a chronic debilitating disease that affects more than 20 mil-

This article was externally peer reviewed.

Submitted 20 September 2006; revised 15 December 2006; accepted 4 January 2007.

From the Department of Family and Community Medicine, Scott and White Memorial Hospital, and Scott, Sherwood, and Brindley Foundation, Texas A\&M University System Health Science Center, College of Medicine, Temple, TX (SNF, MDR, GRC, SM, SM-L); and the Department of Social and Health Behavior, Texas A\&M University System Health Science Center, School of Rural Public Health College Station, TX (MGO).

Funding: This work was funded by the Health Services Research Program of the Texas A\&M University System Health Science Center School of Rural Public Health and Scott and White.

Prior presentation: Portions of the data were presented at the Agency for Healthcare Research and Quality (AHRQ) National Practice-Based Research Network (PBRN) Research Conference, Bethesda, MD, May 15-17, 2006.

Conflict of interest: none declared.

Corresponding author: Samuel N. Forjuoh, MD, DrPH, Department of Family and Community Medicine, Scott and White Santa Fe-Century Square, 1402 West Avenue H, Temple, TX 76504 (E-mail: sforjuoh@swmail.sw.org). lion people in the United States, diabetes is one condition that has benefited from e-health to improve patient outcomes. ${ }^{3}$ For example, the use of the home blood glucose monitor in the late 1980s began to change the way patients with diabetes were monitored. Three studies demonstrated that the use of home glucose monitors improved patient clinical outcomes, including better control of their blood glucose, lowering of their HbA1c levels, and a trend toward decreased progression of diabetic neuropathy and platelet aggregability. ${ }^{4-6}$

The impact of implementing electronic medical records (EMRs) on diabetic care has also been examined, but with mixed results. Although some uncontrolled studies have reported benefits regarding metabolic control, ${ }^{7,8}$ recent controlled studies have demonstrated little or no such benefits besides the EMRs helping to increase the number of tests ordered. ${ }^{9,10}$ Other newer e-health strategies that have been evaluated in diabetes management include the Internet combined with short message service (SMS), ${ }^{11}$ Web-based support systems, ${ }^{12,13}$ electronic clinical reminders incorporated into di- 
abetes self-care education programs, ${ }^{14,15}$ and the PDA. ${ }^{16-20}$

The role of the PDA and other electronic diaries in achieving better diabetes self-care in patients with diabetes was reviewed by Kerkenbush and Lasome, ${ }^{17}$ with conflicting findings regarding reduction in HbA1c levels. ${ }^{18,19}$ Based on the conclusion that the use of electronic diaries could potentially increase patient compliance and improve patient satisfaction, they recommended further studies to determine exactly which patients can benefit most from using PDAs. ${ }^{17}$ In a recent comprehensive and systematic review of published papers on the use of PDAs in medicine, Fisher et $\mathrm{al}^{21}$ also echoed the same sentiments that only a few papers have provided evidence-based information about the use of PDAs in medicine.

Because of the ability of the PDA to keep track of appointments, store phone numbers and addresses, save memos and messages, keep track of tasks with built-in alarms or reminders, and act as a calculator, among others, its use in disease management is receiving increasing attention. ${ }^{16}$ The PDA can also be customized to be more intimate with diabetes selfcare through memory expansion to accommodate the storage of diabetes self-care activity monitoring software programs. ${ }^{16}$ Examples of commercially available programs for use in PDAs for diabetes self-care monitoring include the GlucoPilot Diabetic (www.healthtech.com/compter_glucopilot.html), the UTS Diabetes Palm (www.utracks.com), the EZManager Diabetic (www.animascorp.com), and the Diabetes Pilot (www.diabetespilot.com). Despite the potential utility of the PDA in disease management and the availability of diabetes self-care programs, the feasibility of incorporating PDA use to enhance the self-care activities of patients with diabetes is understudied.

The overall goal of our study is to investigate the feasibility of incorporating PDA use by patients in their diabetes self-care and then to explore among users whether PDA use will lead to improved glycemic control. In this study, we document our initial experiences in testing PDA use for diabetes self-care activity monitoring, highlighting major challenges and identifying patients that are most likely to adopt this technology. Findings from analysis of objective outcome data will be forthcoming after follow-up of all study subjects is completed.
Methods

\section{Study Design and Setting}

This prospective intervention study was conducted in 4 of the 15 clinics of a large university-affiliated, multispecialty group practice associated with an 186,000-member Health Maintenance Organization (HMO) in central Texas. The 4 clinics are the largest within the group practice located within 30 miles of the main hospital and were chosen because of their close proximity to the hospital. Data collection began in 2 of the 4 clinics in September 2005 , later extended to the other 2 clinics to enhance participant recruitment, and is ongoing. Our Institutional Review Board approved the study protocol, and all participants provided written informed consent before enrollment.

\section{Study Participants and Enrollment Methods}

Participants were 18 years of age or older with type 2 diabetes whose last measured $\mathrm{HbA1c}$ was $9.0 \%$ or greater as identified in their medical records through a search of the organization's data warehouse or $8.0 \%$ or greater at their research orientation visit. The lowering of the HbA1c requirement from $9.0 \%$ to $8.0 \%$ was to further enhance participant recruitment due to decreases in $\mathrm{HbA1c}$ values of potential subjects between their identification via medical records and orientation visit. Additional inclusion criteria for study participation were the ability to read, write, and speak English, and willingness and ability to attend 3 research visits. Subjects were excluded if they had a documented alcohol or drug abuse problem, a vision or a dexterity problem, or if they were pregnant or indicated an intention of becoming pregnant within the next 6 months.

The enrollment process consisted of mailing recruitment letters to identified prospective subjects, followed by phone screening of respondents, and subsequent invitation of all eligible subjects for a research orientation visit. First, we enlisted the participation of the physicians in the 4 study clinics. Then we searched the organization's data warehouse for eligible subjects of the physicians with the HbA1c cutoff of $9.0 \%$. Finally, we sent out a list of each physician's eligible subjects, along with predesigned letters of invitation for study participation to the physicians for signed approval. A physician could exclude any subject if he or she did not want them included in the study for any reason. All 
eligible subjects approved by their physicians were invited for study participation by mail, and those interested were asked to call a designated research assistant (RA) to schedule a research orientation visit.

The phone screening of prospective subjects included review of the study inclusion and exclusion criteria and subsequent scheduling of subjects for the research orientation visit. In addition, oral permission was obtained from each subject during the phone call to review their medical records to ascertain some of the exclusion criteria (eg, documented alcohol problem). If any exclusion was found, the subject was notified and the scheduled appointment was cancelled. At the research orientation visit, a written informed consent was obtained from each subject for study enrollment after which HbA1c was checked again to confirm eligibility (ie, $8.0 \%$ or greater).

At the end of each of the 3 required research visits, a \$20 Wal-Mart gift card stipend was given to each participant. The same amount of incentive was given to all subjects who did not qualify for the study at their orientation visit.

\section{Intervention}

The intervention in this study without a control group consisted of providing each participant with: a loaned password-protected, institutional-registered PDA preinstalled with Diabetes Pilot software (www.diabetespilot.com); one-on-one training on the use of the PDA and accompanying preinstalled software by a trained RA; a copy of the training manual; and 1-week follow-up monitoring phone call and ongoing phone support by the RA.

Diabetes Pilot, which was purchased from Digital Altitudes (Mount Prospect, IL), is a software program designed to make diabetes management easier and more accurate than use of traditional paper logs. It has been designed to handle information in a way that is fast and easy to record and review. It has the capabilities of recording blood glucose measurements, insulin and other medication dosages and administration times, meals, exercise, test results, and other notes. In addition, the program can be used to track intake of carbohydrates, calories, fat, protein, and fiber in the foods consumed using an integrated food database that contains information on thousands of foods including hundreds of fast foods. It can also be used to visualize trends in blood glucose using various report formats and graphs as well as to categorize records by time of day or any other preferred system. Finally, the program allows for fast and easy transfer of data into a complementary desktop program for further analysis and communication with others such as one's health care provider.

\section{Training of Participants}

Participants were given instructions on the general features and operations of the PDA as well as the specific features and operations of the Diabetes Pilot software using a pictorial instructional manual that was developed by the RA with input from the software vendor. They were taught the correct way to turn the PDA on and off, to charge and take care of the PDA, to navigate on the PDA, and to enter and delete items as well as the capabilities of the "Notes" feature of the PDA. The different icons on the PDA were explained to them and they were made to actually practice navigation for the RA to see in a hands-on fashion. Finally, the correct procedure for saving data was demonstrated.

Diabetes Pilot features that were covered during the training included entry of blood sugar readings, type and duration of exercise, diet and carbohydrate counts, and medications. After the training, participants were scheduled for return visits after 3 and 6 months. To offset the cost of transportation to the research visits, each participant was given monetary incentive of \$20 stipend per visit.

\section{Data Collection and Instrumentation}

Table 1 summarizes the data collection points in this study. At the research orientation visit (baseline or visit 1), data collection included HbA1c, height, weight, and blood pressure, along with sociodemographic and PDA use data. Height and weight were used to compute body mass index (BMI). The PDA use survey included questions on ever using a computer, having regular access to a computer, using e-mail, using the Internet, ever using a PDA and if yes, how comfortable they were in using the PDA, and whether they currently owned a PDA.

In addition, the RA assessed each participant's computer skills during the training and ranked them as having: (1) no computer skills-absolute lack of computer knowledge and needed additional training; (2) below average- - had difficulty navigating PDA and expressed concern about using the PDA; (3) average - understood most instructions 


\begin{tabular}{|c|c|c|c|c|}
\hline \multirow[b]{2}{*}{ Activity/Data Measurement } & \multicolumn{4}{|c|}{ Timing } \\
\hline & Phone Screening & $\begin{array}{c}\text { Orientation Visit } \\
\text { (Visit 1) }\end{array}$ & $\begin{array}{l}\text { 3-Month Visit } \\
\text { (Visit 2) }\end{array}$ & $\begin{array}{l}\text { 6-Month Visit } \\
\text { (Visit 3) }\end{array}$ \\
\hline Obtain oral consent & $\mathrm{X}$ & & & \\
\hline Review medical record & $X$ & & & \\
\hline Schedule (orientation) visit 1 & $\mathrm{X}$ & & & \\
\hline Obtain written informed consent & & $\mathrm{X}$ & & \\
\hline HbA1c check & & $\mathrm{X}$ & & $\mathrm{X}$ \\
\hline Height & & $\mathrm{X}$ & & \\
\hline Weight & & $\mathrm{X}$ & $\mathrm{X}$ & $\mathrm{X}$ \\
\hline Blood pressure & & $\mathrm{X}$ & $\mathrm{X}$ & $\mathrm{X}$ \\
\hline Sociodemographic/PDA use & & $\mathrm{X}$ & & \\
\hline PDA use tracking & & & $\mathrm{X}$ & $\mathrm{X}$ \\
\hline Diabetes self-care activity (DSCA) & & & $\mathrm{X}$ & $\mathrm{X}$ \\
\hline Health-related quality life (HRQOL-4) & & & $\mathrm{X}$ & $\mathrm{X}$ \\
\hline Loan PDA & & $\mathrm{X}$ & & \\
\hline Initial PDA use training & & $\mathrm{X}$ & & \\
\hline Monitor PDA use & & & $\mathrm{X}$ & $\mathrm{X}$ \\
\hline Schedule (3-month) visit 2 & & $\mathrm{X}$ & & \\
\hline Schedule (6-month) visit 3 & & & $\mathrm{X}$ & \\
\hline Stipend (Wal-Mart certificate for $\$ 20$ ) & & $\mathrm{X}$ & $\mathrm{X}$ & $\mathrm{X}$ \\
\hline Return loaned PDA & & & & $\mathrm{X}$ \\
\hline
\end{tabular}

and had little difficulty navigating PDA; (4) above average - understood almost all instructions and had little to no difficulty using PDA; and (5) extremely above average-may have owned a PDA, understood all instructions, and had no difficulty at all navigating the PDA.

\section{Data Analysis}

To assess any significant differences that could temper or guide our subsequent conclusions, we compared our final study participants with the nonparticipants on available characteristics using the $\chi^{2}$ test. Baseline HbA1c values were grouped into quartiles whereas baseline BMI values were grouped into quintiles. We also computed changes in HbA1c values at 6 months from baseline for a subset of the subjects who had completed the 6-month follow-up. Statistical significance was set at the $P<.05$ level. We then performed descriptive, univariate analyses to compute means, medians, and standard deviations as well as percentages of baseline continuous variables. Finally, identified research and practical challenges were grouped by theme.

\section{Results}

\section{Recruitment of Study Participants}

Five hundred and fifty letters were sent out to potential subjects inviting them for participation in the study. However, only 98 interested subjects $(17.8 \%)$ responded and called to schedule an orientation visit. Of these respondents, 18 were never contacted after we reached our enrollment goal. Of the remaining 80 respondents, 43 (53.8\%) met all study inclusion criteria. The reasons for exclusion were subjects' HbA1c falling below $8.0 \%$ at the orientation visit $(n=27)$, identification of a substance abuse problem $(\mathrm{n}=1)$, canceling the orientation appointment and not rescheduling or calling again $(\mathrm{n}=7)$, and expressing no further interest in the study $(n=2)$. One subject dropped out of the study before the 1-week follow-up monitoring phone call, and 13 others dropped out before the 3-month follow-up visit.

Table 2 summarizes the differences between the final study subjects who agreed to enroll in the study (participants) and those subjects who did not (nonparticipants). There were no statistically significant differences between the 2 groups by age group, sex, or race/ethnicity. However, study participants were significantly more likely to have in- 
Table 2. Comparison of Study Participants and Nonparticipants

\begin{tabular}{|c|c|c|c|c|}
\hline Characteristic & $\begin{array}{l}\text { Eligible Subjects } \\
\quad(\mathrm{N}=550)\end{array}$ & $\begin{array}{c}\text { Participants* } \\
(\mathrm{N}=43) \text { n }(\%)\end{array}$ & $\begin{array}{l}\text { Nonparticipants } \\
(\mathrm{N}=507) \mathrm{n}(\%)\end{array}$ & $\begin{array}{c}P \\
\text { Value }\end{array}$ \\
\hline Age group (years) & & & & $0.99 \dagger$ \\
\hline$<50$ & 174 & $12(29.3)$ & $162(32.0)$ & \\
\hline 50 to 59 & 186 & $16(39.0)$ & $170(33.5)$ & \\
\hline$\geq 60$ & 188 & $13(31.7)$ & $175(34.5)$ & \\
\hline Sex & & & & $0.09 \ddagger$ \\
\hline Male & 279 & $16(37.2)$ & $263(51.9)$ & \\
\hline Female & 271 & $27(62.8)$ & $244(48.1)$ & \\
\hline Race/ethnicity & & & & $0.05 \dagger$ \\
\hline White (Non-Hispanic) & 289 & $27(62.8)$ & $262(51.7)$ & \\
\hline Hispanic & 101 & $9(20.9)$ & $92(18.1)$ & \\
\hline Black/African American & 94 & $5(11.6)$ & $89(17.6)$ & \\
\hline Other & 66 & $2(4.7)$ & $64(12.6)$ & \\
\hline Insurance type & & & & $0.03 \ddagger$ \\
\hline $\mathrm{HMO}$ & 484 & $33(76.7)$ & $451(89.0)$ & \\
\hline Other & 66 & $10(23.3)$ & $56(11.0)$ & \\
\hline HbA1c $(\%) \S$ & & & & $0.03 \dagger$ \\
\hline$<9.0$ & 221 & $11(25.6)$ & $210(41.4)$ & \\
\hline 9.0 to 9.9 & 118 & $10(23.3)$ & $108(21.3)$ & \\
\hline$\geq 10$ & 211 & $22(51.1)$ & $189(37.3)$ & \\
\hline
\end{tabular}

* May not add to total due to missing data.

$\dagger \chi^{2}$ test for linear trend.

$\ddagger$ Yates corrected $\chi^{2}$ test.

$\S$ Baseline HbA1c for participants and the most recent HbA1c in patient's record for nonparticipants.

surance other than the HMOs and be in worse glycemic control than the nonparticipants.

\section{Demographic Characteristics of Study Participants}

Participants' mean age was 55.2 years $(\mathrm{SD}=10.1$; range $=35$ to 77 ; median $=54)$ and their mean baseline $\mathrm{HbA1} \mathrm{c}$ was $10.0 \%$ ( $\mathrm{SD}=1.5$; range $=8$ to 14 ; median $=9.7$ ). Table 3 summarizes the sociodemographic characteristics of the final study participants. Approximately one third were younger than 50 years and another third were aged 60 years or older. The majority were female $(62.8 \%)$ and white, non-Hispanic (62.8\%); $83.7 \%$ had at least some college education, and most reported an annual household income of $\$ 30,000$ to $\$ 69,999$. The vast majority was insured through the organization's HMO (76.7\%), with the remaining participants having other insurance plans.

Slightly more than one quarter of the participants had a baseline HbAlc value below 9.0\%, whereas $20.9 \%$ had $\mathrm{HbA1c}$ of $11.0 \%$ or greater. Only a small minority $(7.0 \%)$ had a normal BMI (18.5 to 24.9 ), with $16.3 \%$ having a BMI of 25.0 to 29.9 (or overweight). The remaining participants were obese with a BMI of 30.0 or greater, including $27.9 \%$ morbidly obese participants with BMI of 40.0 or greater.

\section{Participants' Self-Reported Computer Literacy and Assessed Computer Skills}

The vast majority of the participants reported being computer literate: $90.7 \%$ reported having used a computer in the past; $87.8 \%$ reported having regular access to a computer; $86.0 \%$ reported using the Internet regularly; and $83.7 \%$ reported using e-mail regularly. However, only 8 subjects $(18.6 \%)$ reported ever using a PDA, half of whom reported owning one and also being comfortable using the device.

The computer skills of more than half of the participants were assessed to be higher than average, with $18.6 \%$ assessed as having skills below average and $14.0 \%$ assessed as having no computer skills. Although nearly one third of the participants were assessed to have extremely above-average skills (30.2\%), 25.6\% were assessed as having above-average skills, and $11.6 \%$ having average skills. 
Table 3. Sociodemographic Characteristics of Study Participants

\begin{tabular}{|c|c|c|}
\hline Characteristic & Number* & $\%$ \\
\hline \multicolumn{3}{|l|}{ Age group (years) } \\
\hline$<50$ & 12 & 29.3 \\
\hline 50 to 59 & 16 & 39.0 \\
\hline$\geq 60$ & 13 & 31.7 \\
\hline \multicolumn{3}{|l|}{ Sex } \\
\hline Male & 16 & 37.2 \\
\hline Female & 27 & 62.8 \\
\hline \multicolumn{3}{|l|}{ Race/ethnicity } \\
\hline White (non-Hispanic) & 27 & 62.8 \\
\hline Hispanic & 9 & 20.9 \\
\hline Black/African American & 5 & 11.6 \\
\hline Other & 2 & 4.7 \\
\hline \multicolumn{3}{|l|}{ Education } \\
\hline Up to high school/GED & 7 & 16.3 \\
\hline Some college & 19 & 44.2 \\
\hline College degree/graduate degree & 17 & 39.5 \\
\hline \multicolumn{3}{|l|}{ Annual family income } \\
\hline$<\$ 30,000$ & 13 & 31.0 \\
\hline$\$ 30,000$ to $\$ 69,999$ & 18 & 42.9 \\
\hline$\geq \$ 70,000$ & 11 & 26.1 \\
\hline \multicolumn{3}{|l|}{ Insurance type } \\
\hline $\mathrm{HMO}$ & 33 & 76.7 \\
\hline Other & 10 & 23.3 \\
\hline \multicolumn{3}{|l|}{ HbA1c (\%) } \\
\hline 8.0 to 8.9 & 12 & 27.9 \\
\hline 9.0 to 9.9 & 14 & 32.6 \\
\hline 10.0 to 10.9 & 8 & 18.6 \\
\hline$\geq 11.0$ & 9 & 20.9 \\
\hline \multicolumn{3}{|l|}{ BMI } \\
\hline 18.5 to 24.9 & 3 & 7.0 \\
\hline 25.0 to 29.9 & 7 & 16.3 \\
\hline 30.0 to 34.9 & 13 & 30.2 \\
\hline 35.0 to 39.9 & 8 & 18.6 \\
\hline$\geq 40.0$ & 12 & 27.9 \\
\hline
\end{tabular}

*Numbers may not add to totals due to missing data and rounding.

\section{Training of Study Participants}

The initial training on the features and operations of the PDA and accompanying software lasted a mean of 57.1 minutes $(\mathrm{SD}=16.6$; range $=30$ to 90). Including the 1 -week monitoring phone calls to all participants, the RA made a total of 117 phone calls to participants, lasting a mean of 5 minutes. All 42 participants were called twice, 15 were called 3 times, 14 were called 4 times, and 4 participants were called 5 times.

\section{Cost of the Intervention}

The cost of the intervention per participant in this study was assessed as approximately $\$ 650$. This cost included the cost of the PDA (\$200) and software (\$25), the time spent by the RA to develop the pictorial instructional manual (\$65), the time spent by the RA for the initial training, monitoring, and retraining (\$220), monetary incentives $(\$ 60)$, and cost of the HbA1c testing $(\$ 80)$.

\section{Challenges Encountered in Study}

Table 4 lists our major challenges by time of study and how we addressed each of them. Before subject enrollment into the study, our major challenge concerned the selection of the appropriate PDA operating system. We selected the Palm operating system instead of the Windows operating system because of its ease of use and availability of more software programs for it. Other challenges included choice of appropriate device and software as well as the appropriate teaching tool to provide the instructions. We selected the Tungsten E because of its higher-resolution screen and its nonvolatile memory and the Diabetes Pilot mainly because of prior collaboration with its developer.

Our major challenge during subject enrollment was subject recruitment itself, partly because of decreases in HbA1c values of potential subjects between their identification via electronic medical records and research orientation visit and partly because of the initial low response to our mailed letters of recruitment. A related challenge was budgetary constraints due to having to provide pledged incentives to potential subjects who failed to meet all study inclusion criteria at the orientation visit. Another challenge during this phase of the study related to federal regulatory requirements (Clinical Laboratory Improvement Amendments of 1988) regarding HbA1c testing.

Participants' frustration with entering daily dietary information leading to their consideration to drop out of the study was the major challenge after subject enrollment. Other challenges we encountered at this stage included participants' loss of their instructional folders, difficulty with data entry, and loss of data due to incorrect saving technique after entry. Finally, we experienced difficulty in retrieving our PDAs from the few subjects who later dropped out of the study.

\section{Preliminary Analysis of HbA1c Reduction at 6 Months from Baseline}

Preliminary analysis based on 9 participants who have completed the 6-month follow-up shows a 


\begin{tabular}{|c|c|}
\hline Challenge & Response \\
\hline \multicolumn{2}{|l|}{ Prior to subject enrollment } \\
\hline 1. Selection of appropriate operating system (OS) & $\begin{array}{l}\text { Selected the Palm OS instead of the Windows OS due to } \\
\text { ease of use and availability of more software programs }\end{array}$ \\
\hline 2. Selection of appropriate device & $\begin{array}{l}\text { Selected the Tungsten E instead of Zire } 21 \text { or Zire } 31 \\
\text { due to its higher-resolution screen and its nonvolatile } \\
\text { memory }\end{array}$ \\
\hline 3. Selection of appropriate software and vendor & $\begin{array}{l}\text { Selected the Diabetes Pilot software from Digital } \\
\text { Altitudes due to prior collaboration, ease of use, and } \\
\text { completeness }\end{array}$ \\
\hline 4. Teaching tool & Developed a pictorial instructional manual in-house \\
\hline \multicolumn{2}{|l|}{ During subject enrollment } \\
\hline $\begin{array}{l}\text { 5. Low subject recruitment due to changes in HbAlc values } \\
\text { between participant selection and orientation visit }\end{array}$ & Revised HbA1c cutoff level from $9.0 \%$ to $8.0 \%$ \\
\hline $\begin{array}{l}\text { 6. Low subject recruitment due to low response to mailed } \\
\text { letters of recruitment }\end{array}$ & $\begin{array}{l}\text { Used more proactive strategies (eg, mounting a poster at } \\
\text { each clinic) }\end{array}$ \\
\hline $\begin{array}{l}\text { 7. Budgetary constraints due to having to provide pledged } \\
\text { incentives to patient who fail to qualify at orientation } \\
\text { visit }\end{array}$ & Requested additional funds from department \\
\hline $\begin{array}{l}\text { 8. Regulatory requirement of HbA1c testing that precludes } \\
\text { testing in non-CLIA locations }\end{array}$ & $\begin{array}{l}\text { Negotiated with organizational authorities for CLIA } \\
\text { certification at our preferred research location }\end{array}$ \\
\hline \multicolumn{2}{|l|}{ After subject enrollment } \\
\hline 9. Loss of instructional manual by 2 participants & Replaced lost manuals \\
\hline $\begin{array}{l}\text { 10. Loss of data due to participant's failure to properly save } \\
\text { entered data }\end{array}$ & Retrained participants \\
\hline $\begin{array}{l}\text { 11. Difficulties with data entry so choosing to enter all } \\
\text { activities in a book }\end{array}$ & Retrained participants \\
\hline $\begin{array}{l}\text { 12. Participants' frustration with daily dietary entry leading } \\
\text { to their consideration to drop out of the study }\end{array}$ & $\begin{array}{l}\text { Informed participants that daily dietary entry is not } \\
\text { required }\end{array}$ \\
\hline 13. Loss of PDA charger by 1 participant & Replaced lost charger \\
\hline 14. Failure to return PDA after dropping out of study & Made several calls to subject to return the PDA \\
\hline
\end{tabular}

CLIA, Clinical Laboratory Improvement Amendments (of 1988).

significant reduction in $\mathrm{HbA1c}$ values after 6 months from baseline $(9.4 \%$ to $8.1 \% ; P<.001)$. For 1 particular participant, there was a $35 \%$ drop in HbA1c levels from a baseline of $12.4 \%$ to $8.1 \%$ after 6 months.

\section{Discussion}

The PDA has been shown theoretically and empirically to have great potential as a mechanism for patients to use in maintaining an electronic diary and sharing it with their health care providers either remotely or during scheduled appointments. ${ }^{16-24} \mathrm{Be}-$ cause of the novelty of using PDAs for diabetes selfcare monitoring, ${ }^{18-20}$ we were mainly interested in this feasibility study to determine whether patients would be willing to even consider the use of the PDA in their disease management. Therefore, although the data may not justify any conclusions about which patients are most likely to adopt PDA use and succeed in their glycemic control, the data do illuminate on the characteristics of patients who may consider adopting this technology in their diabetic self-care. In addition, the data uncover some practical challenges of concern to the practicing family physician who may want to consider encouraging patients in their practice to adopt PDAs for their diabetes self-care.

Although, our data show that it is feasible to incorporate PDA use in diabetes self-care with possible improvement in glycemic control based on our preliminary analysis, several research and practical challenges of attempting to incorporate this e-health in diabetes self-care do exist. The major challenges of specific concern to the practicing family physician we found included few subjects agreeing to enroll in the program even though it was free, subjects who agreed to enroll being generally different from those who decided not to enroll, some PDAs not returned, and the relatively high cost of the intervention. 
We found that patients likely to even adopt this technology are those educated ones with a medium to high income and some prior computer knowledge. These findings are consistent with those found for users of any new technology such as the Internet and e-mail in many diverse settings. ${ }^{25-27}$ In a study to assess e-mail use in our own health care system, we found the highest use prevalence in a clinic located in a university city, where the clinic clientele had the highest educational attainment. ${ }^{25}$ It is important to note that although this study attracted well educated, primarily computer-literate people, those with clinical risks were also included. The study participants were primarily overweight or obese, people at high risk for complications of diabetes who probably saw this new technology as a way of improving their diabetes management.

We estimated the cost per participant in this feasibility study to be approximately $\$ 650$, including the cost of the PDA, the diabetes management software, and the training, monitoring, and retraining time as well as the monetary incentives and cost of HbA1c testing. However, in a real clinical practice setting, the cost per participant should be much less for several reasons. First, the cost of the training manual, which has already been developed and can be edited and shared freely with practicing physicians, will be eliminated. Second, prices of PDAs and associated software continue to decrease. Finally, in a real clinical setting, patients will not expect any monetary incentives and the cost of the HbA1c will also be offset by usual clinical care costs and taken up by their health insurance.

From research perspective, the major challenges that we encountered in this endeavor seem to be related to training and costs. This is in contrast to a previous study that found technological malfunctions as the major challenge or barrier. ${ }^{20}$ The training required for this effort was found to be enormous. For example, because many proprietary software programs come with voluminous manuals that are likely to overwhelm patients, it may be necessary to develop one's own manual for use in the training of participants. This can be a huge task as was the case in this pilot study. It was also necessary to retrain the few people who were not as computer literate as the majority, particularly regarding the correct or proper way to save entered data into the PDA.
The other challenge of this technological endeavor was the burden of daily data entry. This might have been compounded by participants' limited time due to family and job constraints and their inability to fit the program into their daily activities as found by others. ${ }^{28}$ In fact, several participants became so frustrated with the daily dietary entry that some of them contemplated dropping out of the study. This challenge, with the potential of huge study attrition, was resolved by getting back to the participants and informing them that daily dietary entry was not necessarily required. This challenge obviously calls for constant review of software programs to ensure that the tasks required of users are feasible and are as practical as possible.

Our major research challenge of initial low subject enrollment was partly resolved by expanding our recruitment to other clinics, which resulted in better subject enrollment and also explains why we had 18 more interested subjects than needed to reach our enrollment target. This was also the reason why we lowered the HbAlc requirement from $9.0 \%$ at subject's identification in the EMR to $8.0 \%$ at the research orientation visit.

Findings from this pilot study ought to be interpreted vis-a-vis some study limitations. First, the study clinics were self-selected. Therefore, the findings may not be generalized to other clinics in our own health care system or other HMOs. Second, the study participants differed from eligible potential nonparticipants by their HbA1c levels and insurance type. Other important variables such as education and family income could not be compared between participants and nonparticipants because we did not interview the nonparticipants to obtain such information, which could also not be obtained from the EMR. In addition, it is possible that some of those who refused to sign up might have had some prior knowledge about the cumbersome dietary entry activities associated with diabetes management software, which could have negatively influenced study participation. Participants' self-perception of the benefit of the program in helping them manage their disease may have also differed but this variable was not measured. Finally, participants' ongoing participation in the study may partly have been influenced by the personality of the research staff who provided the ongoing support, encouragement, and constant reassurance.

Although this feasibility study has shown that it is feasible to incorporate PDA use in diabetes self- 
care, it is important to find ways of making this technology easier and more acceptable to a broader population who may be at a higher risk. For example, patients need to be told by their physicians upfront that daily dietary entry would not be necessarily required. Future studies need to examine ways of overcoming barriers to PDA use and to design methods to track data in real-time environment and expedite communication between an Internet service provider and a central data repository with feedback to patient's providers. In addition, future studies need to compare program costs with potential benefits such as prevention or avoidance of diabetes complications in a cost-benefit analysis as well as link PDA adoption and use to outcomes, particularly that of glycemic control.

We thank Ricky O'Banon and Sonia Holleman for help with data acquisition, Mohammad H. Rajab for statistical support, Mike Biewenga for his input in putting together the training manual and other consultations on the "Diabetes Pilot" management software, and Laura Gibson for secretarial help.

\section{References}

1. Speicher CE. The bottom line. Can portable blood glucose monitoring improve the outcomes of diabetic patients? Am J Clin Pathol. 1991;95:112-6.

2. Page SR, Peacock I. Blood glucose monitoring: does technology help? Diabet Med. 1993;10:793-801.

3. Watts NB, Keffer JH. Practical Endocrinology. 4th Ed. Philadelphia: Lea and Febiger, 1989;170-2.

4. Lam KS, Ma JT, Chan EY, Yeung RT. Sustained improvement in diabetic control on long-term selfmonitoring of blood glucose. Diabet Res Clin Pract. 1986;2:165-71.

5. Sjoberg S, Carlson A, Rosenquist U, Ostman J. Health attitudes, self-monitoring of blood glucose, metabolic control and residual insulin secretion in type I diabetic patients. Diabetic Med. 1988;5:44953.

6. Yeo PP, Thai AC, Wang KW, et al. Home blood glucose monitoring, glycemic control, and diabetic complications. Ann Acad Med Singapore. 1985;14: 247-51.

7. Sperl-Hillen J, O'Connor PJ, Carlson RR, et al. Improving diabetes care in a large health care system: an enhanced primary care approach. Jt Comm J Qual Improv. 2000;26:615-22.

8. Sutherland JE, Hoehms JD, O'Donnell B, Wiblin RT. Diabetes management quality improvement in a family practice residency program. J Am Board Fam Pract. 2001;14:243-51.

9. Meigs JB, Cagliero E, Dubey A, et al. A controlled trial of web-based diabetes disease management: the
MGH diabetes primary care improvement project. Diabetes Care. 2003;26:750-7.

10. O'Connor PJ, Crain AL, Rush WA, Sperl-Hillen JM, Gutenkauf JJ, Duncan JE. Impact of an electronic medical record on diabetes quality of care. Ann Fam Med. 2005;3:300-6.

11. Kwon HS, Cho JH, Kim HS, et al. Development of web-based diabetic patient management system using short message service (SMS). Diabetes Res Clin Pract. 2004;66 (Suppl 1):S133-7.

12. Baker AM, Lafata JE, Ward RE, Whitehouse F, Divine G. A web-based diabetes care management support system. Jt Comm J Qual Improv. 2001;27: 179-90.

13. Shea S, Starren J, Weistock RS, et al. Columbia University's Informatics for Diabetes Education and Telemedicine (IDEATel) Project: rationale and design. J Am Med Inform Assoc. 2002;9:49-62.

14. Chima CS, Farmer-Dziak N, Cardwell P, Snow S. Use of technology to track program outcomes in a diabetes self-management program. J Am Diet Assoc. $2005 ; 105: 1933-8$.

15. Sequist TD, Ghandhi TK, Karson AS, et al. A randomized trial of electronic clinical reminders to improve quality of care for diabetes and coronary artery disease. J Am Med Inform Assoc. 2005;12:431-7.

16. Hansen B. Handheld computers in diabetes management. Diabetes Self Manag. 2002;19:43-4, 48-9.

17. Kerkenbush NL, Lasome CEM. The emerging role of electronic diaries in the management of diabetes mellitus. AACN Clin Issues. 2003;14:371-8.

18. Tsang MW, Mok M, Kam G, et al. Improvement in diabetes control with a monitoring system based on a handheld, touch-screen electronic diary. J Telemed Telecare. 2001;7:47-50.

19. Compaq technology delivers patient support in key diabetes program. Available at: www.compaq.ca/English/enterprise/success/government/diabetes.htm. Accessed June 20, 2002.

20. Keshavjee K, Lawson ML, Malloy M, Hubbard S, Grass M. Technology failure analysis: Understanding why a diabetes management tool developed for a personal digital assistant (PDA) didn't work in a randomized control trial. AMIA Annu Symp Proc. $2003 ; 889$.

21. Fisher S, Stewart TE, Mehta S, Wax R, Lapinsky SE. Handheld computing in medicine. J Am Med Inform Assoc. 2003;10:139-49.

22. Chang BL, Omery A. Use of personal digital assistants by adolescents with severe asthma. ACCN Clinical Issues. 2003;14:379-91.

23. Gururajan R. A study of the use of hand-held devices in an emergency department. J Telemed Telecare. 2004;10 (Suppl. 1) S1:33-5.

24. Burke LE, Warziski M, Starrett T, et al. Self-monitoring dietary intake: current and future practices. J Ren Nutr. 2005;15:281-90.

25. Couchman GR, Forjuoh SN, Rascoe TG. E-mail 
communications in family practice: what do patients expect? J Fam Pract. 2001;50:414-18.

26. Kleiner KD, Akers R, Burke BL, Werner EJ. Parent and physician attitudes regarding electronic communication in pediatric practices. Pediatrics. 2002;109: 740-4.

27. Baker L, Wagner TH, Singer S, Bundorf MK. Use of the Internet and e-mail for health care information: results from a national survey. JAMA. 2003; 289:2400-6.

28. Ralston JD, Revere D, Robins LS, Goldberg HI. Patients' experience with a diabetes support programme based on an interactive electronic medical record: qualitative study. BMJ. 2004;328:1159. 